
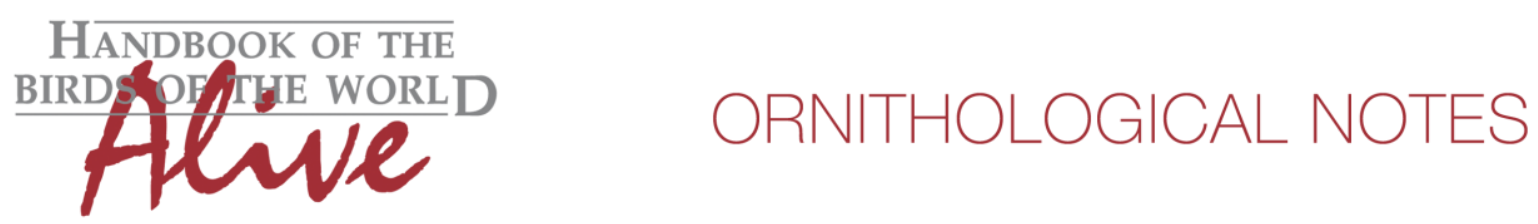

\title{
Notes on the vocalizations of Greenish Elaenia (Myiopagis viridicata)
}

Peter Boesman

In the following we briefly analyze and compare voice of the different races of Greenish Elaenia (Myiopagis viridicata). We also try to quantify the extent of any vocal differences using the criteria proposed by Tobias et al. (2010), as a support for taxonomic review. We have made use of sound recordings available on-line from Xeno Canto (XC).

As there aren't many recordings of dawn song available, we have only compared day-time calls (Fig. 1):

Group 1: M. v. jaliscensis, M. v. minima, M. v. placens, M. v. pacifica Commmonest day-time call of this group is a long high-pitched call (without any buzzy tone quality), initially sharply dropping, then more gradually dropping or even flat, then often again sharply dropping "tsseeuu" (sometimes bisyllabic tsee-tsew) There is a lot of variation in note-length and frequency range, but most are easily recognized. The most extreme calls are longer and start at higher pitch than any other race.

E.g. max. freq. up to $9000 \mathrm{~Hz}$, length up to 1 s.

\section{Group 2: M.v. accola (in Central American region)}

Commonest day-time call is a short, very buzzy overslurred whistle "srreew", sometimes in pairs of two slightly different notes "srreee..srew". Notes are never longer than 0.45 s and never higher than $6000 \mathrm{~Hz}$.

Group 3: M. v. pallens M. v. zuliae M. v. restricta (Caribbean region)

Commonest day-time call is a short, buzzy note, often bisyllabic "srreereew", less often rather monosyllabic and descending. Notes are never longer than $0.5 \mathrm{~s}$ and never higher than $6000 \mathrm{~Hz}$ (descending note slightly higher).

\section{Group 4: M. v. implacens (Tumbes region)}

Commonest day-time call is a short, fairly high-pitched bisyllabic "tsee-ee", less often monosyllabic and descending. Similar to group 3, but seemingly higher-pitched and much less buzzy. Notes are never longer than $0.5 \mathrm{~s}$ and never higher than $7500 \mathrm{~Hz}$.

\section{Group 5: M. v. viridicata}

Commonest day-time call is a short, buzzy note, often bisyllabic "srreereew", less often monosyllabic and descending. Very much like group 3. Notes are never longer than $0.5 \mathrm{~s}$ and never higher than $6000 \mathrm{~Hz}$ (descending note slightly higher). 


\section{HANDBOOK OF THE BIRDSPF THE WORLD}
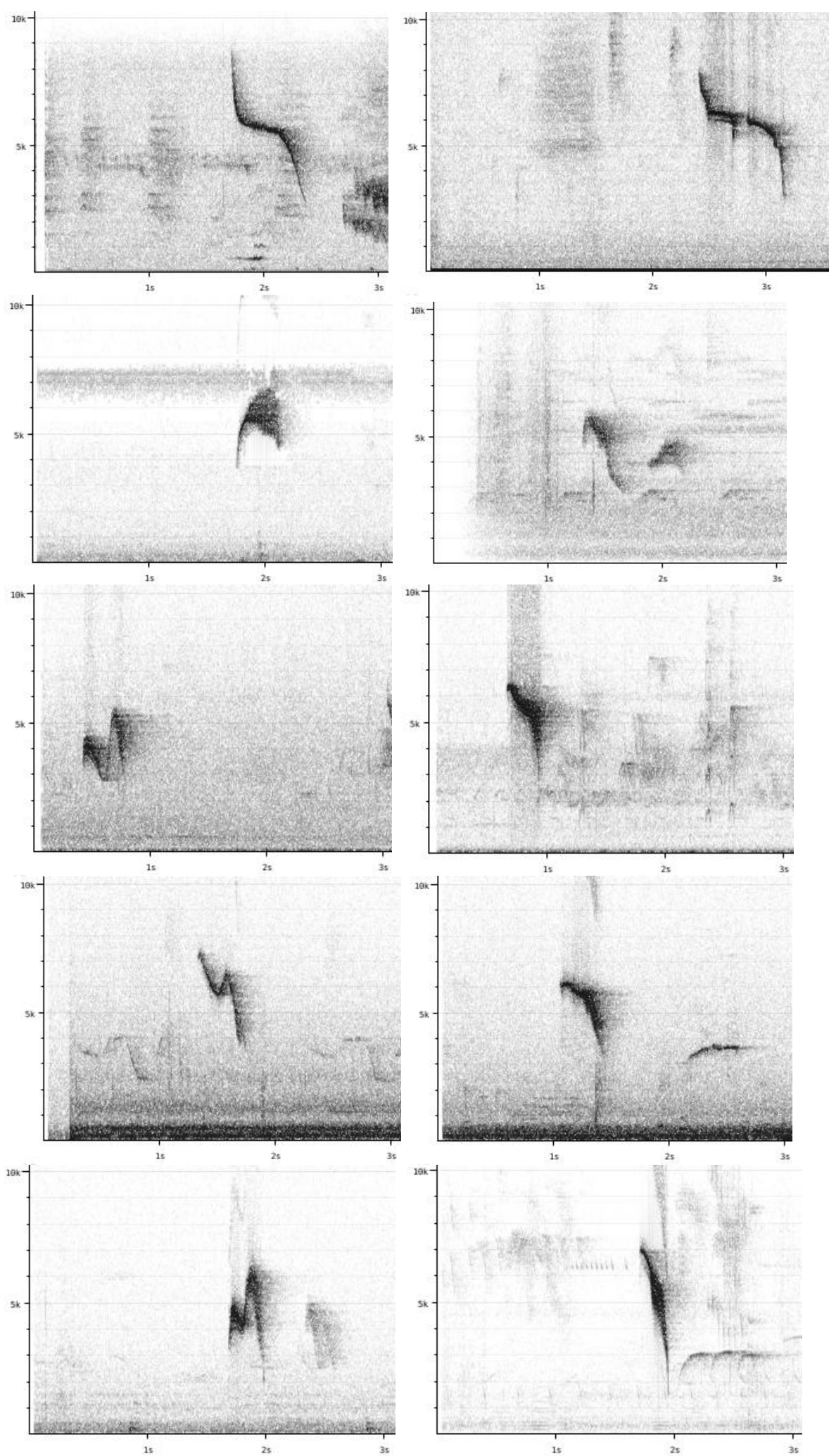

Figure 1: top to bottom: commonest day-time call of resp. Groups 1,2,3,4 and 5 

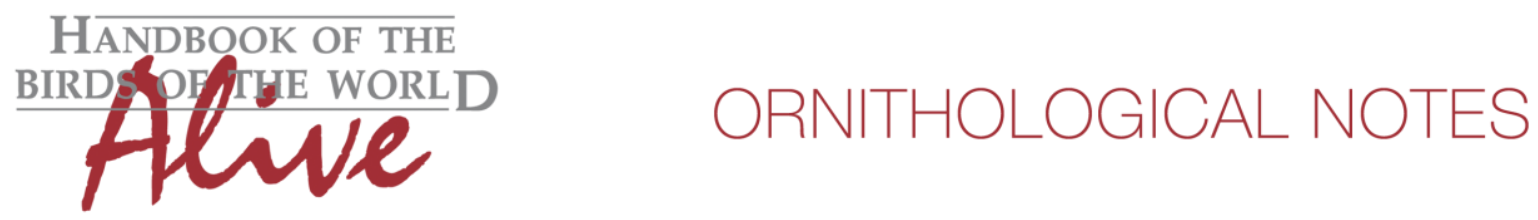

From this brief analysis, it is clear that group 1 is most different from all other groups. The long, high-pitched gradually descending notes are diagnostic.

Besides these typical calls, birds also utter shorter versions of these calls, which then differ hardly from the other groups. It is not clear if these calls have another functionality or not, as comparison should obviously be between homologous calls.

Group 2 also stands apart, because of the mainly very buzzy overslurred whistles. A more extensive analysis would however be needed, as we have not checked that many recordings.

Group 3 and 5 are very similar, and while group 4 is slightly less buzzy and higher-pitched, note shape is very similar.

All in all, we can conclude that especially the Mexican group is standing apart, but only part of its vocabulary is truly diagnostic. To a lesser extent, also group 2 from Central America shows diagnostic features. All South-American races show at most minor vocal differences.

This note was finalized on 28th July 2015 , using sound recordings available on-line at that moment. We would like to thank in particular the many sound recordists who placed their recordings for this species on XC.

\section{References}

Tobias, J.A., Seddon, N., Spottiswoode, C.N., Pilgrim, J.D., Fishpool, L.D.C. \& Collar, N.J. (2010). Quantitative criteria for species delimitation. Ibis 152(4): 724-746.

\section{Recommended citation}

Boesman, P. (2016). Notes on the vocalizations of Greenish Elaenia (Myiopagis viridicata). HBW Alive Ornithological Note 136. In: Handbook of the Birds of the World Alive. Lynx Edicions, Barcelona. (retrieved from http://www.hbw.com/node/932059 on 10 August 2016). 